\title{
A METHOD FOR PROVING SOME INEQUALITIES ON MIXED TRIGONOMETRIC POLYNOMIAL FUNCTIONS
}

\author{
Branko MalešEvić AND MilicA MaKragić
}

Abstract. In this article we present a method for proving a class of inequalities of the form (??). The method is based on the precise approximations of the sine and cosine functions by Maclaurin polynomials of given order. By using this method we present new proofs of some inequalities of C.-P. Chen, W.-S. Cheung [J. Inequal. Appl. 2012:72 (2012)] and Z.-J. Sun, L. Zhu [ISRN Math. Anal. (2011)].

Mathematics subject classification (2010): 26D05, 41A10.

Keywords and phrases: Trigonometric inequalities, approximations of the sine and cosine, Maclaurin polynomials.

\section{REFERENCES}

[1] D. Aharonov, U. Elias, Improved inequalities for trigonometric functions via Dirichlet and Zeta functions, Math. Inequal. Appl., 16 (3) (2013), 851-859.

[2] G. AlireZAEI, A Sharp Double Inequality for the Inverse Tangent Function, arXiv:1307.4983 (2013), 6 pages.

[3] B. BANJAC, M. MAKRAgIĆ, B. MALEŠEviĆ, Some notes on a method for proving inequalities by computer, Results Math., DOI 10.1007/s00025-015-0485-8, (2015).

[4] B. A. Bhayo, J. Sandor, On Carlson's and Shafer's inequalities, Probl. Anal. Issues Anal., 3 (21) Issue 1 (2014), 3-15.

[5] C. P. CHEN, Sharp Wilker and Huygens type inequalities for inverse trigonometric and inverse hyperbolic functions, Integral Transforms Spec. Funct., 23 (12) (2012), 865-873.

[6] C. P. Chen, W. S. Cheung, Sharpness of Wilker and Huygens type inequalities, J. Inequal. Appl., 2012:72 (2012), 11 pages.

[7] C. P. Chen, J. SAndor, Sharp inequalities for trigonometric and hyperbolic functions, J. Math. Inequal., 9 (1) (2015), 203-217.

[8] J. D'AURIZIO, Refinements of the Shafer-Fink inequality of arbitrary uniform precision, Math. Inequal. Appl., 17 (4) (2014), 1487-1498.

[9] L. Debnath, C. Mortici, L. Zhu, Refinements of Jordan-Stečkin and Becker-Stark Inequalities, Results Math., 67 Issue 1-2 (2015), 207-215.

[10] B. Dong, B. YU AND Y. YU, A symmetric homotopy and hybrid polynomial system solving method for mixed trigonometric polynomial systems, Math. Comp., 83 (2014), 1847-1868.

[11] C. V. Durell, A. Robson, Advanced Trigonometry, G. Bell and Sons, London (1930).

[12] R. Godement, Analysis I: Convergence, Elementary functions, Springer-Verlag, (2004).

[13] B. N. GuO, Q. M. LUO, F. QI, Monotonicity results and inequalities for inverse hyperbolic sine function, J. Inequal. Appl., 2013:536 (2013), 6 pages.

[14] B. N. GUO, Q. M. LUO, F. QI, Sharpening and generalizations of Shafer-Fink's double inequality for the arc sine function, Filomat, 27:2 (2013), 261-265.

[15] B. N. Guo, F. QI, Alternative proofs for inequalities of some trigonometric functions, Internat. J. Math. Ed. Sci. Tech., 39:3 (2008), 384-389.

[16] B. N. GUO, B. M. QIAO, F. QI, W. LI, On new proofs of Wilker's inequalities involving trigonometric functions, Math. Inequal. Appl., 6 (1) (2003), 19-22. 
[17] Y. HU, C. MorTici, A lower bound on the sinc function and its application, TSWJ - The Scientific World Journal, 2014 (2014), 4 pages, Article ID 571218.

[18] W. D. JiAng, Q. M. LuO, F. QI, Refinements and Sharpening of some Huygens and Wilker Type Inequalities, TJANT - Turkish Journal of Analysis and Number Theory, 2 (4) (2014), 134-139.

[19] W. D. Jiang, F. QI, Some sharp inequalities involving Seiffert and other means and their concise proofs, Math. Inequal. Appl., 15 (4) (2012), 1007-1017.

[20] J. Kennedy (editor), Interpreting Gödel: Critical essays, Cambridge Univ. Press 2014, Chapter: B. Poonen: Undecidable problems: a sampler, pp. 211-241, (http://www-math.mit.edu/ poonen/ papers/sampler.pdf).

[21] R. Klen, M. Visuri, M. Vuorinen, On Jordan Type Inequalities for Hyperbolic Functions, J. Inequal. Appl. (2010), 14 pages, Article ID 362548.

[22] V. A. Krechmar, A Problem Book in Algebra, Mir Publishers, Moscow (1978).

[23] B. MALEŠEvić, B. BANJAC, I. Jovović, A proof of two conjectures of Chao-Ping Chen for inverse trigonometric functions, arXiv:math/ 1508.06947 (2015).

[24] G. Milovanović, M. Rassias (editors), Analytic Number Theory, Approximation Theory and Special Functions, Springer 2014, Chapter: G. D. Anderson, M. Vuorinen, X. Zhang: Topics in Special Functions III, pp. 297-345.

[25] D. S. Mitrinović, Analytic Inequalities, Springer-Verlag, (1970).

[26] C. Mortici, The Natural Approach of Wilker-Cusa-Huygens Inequalities, Math. Inequal. Appl., 14 (3) (2011), 535-541.

[27] C. Mortici, A subtly analysis of Wilker inequality, Appl. Math. Comput., 231 (2014), 516-520.

[28] C. MoRTICI, H. M. SRIVASTAVA, Estimates for the arctangent function related to Shafer's inequality, Colloq. Math., 136 (2) (2014), 263-270.

[29] E. Neuman, J. SAndor, On some inequalities involving trigonometric and hyperbolic functions with emphasis on the Cusa-Huygens, Wilker and Huygens inequalities, Math. Inequal. Appl., 13 (4) (2010), 715-723.

[30] E. Neuman, J. SAndor, Optimal inequalities for hyperbolic and trigonometric functions, Bull. Math. Anal. Appl., 3 Issue 3 (2011), 177-181.

[31] A. Y. OZBAn, A new refined form of Jordan's inequality and its applications, Appl. Math. Lett., 19 (2006), 155-160.

[32] F. QI, Q. M. LuO, B. N. GuO, A simple proof of Oppenheim's double inequality relating to the cosine and sine functions, J. Math. Inequal., 6 (4) (2012), 645-654.

[33] J. SANDOR, On new refinements of Kober's and Jordan's trigonometric inequalities, NNTDM - Notes on Number Theory and Discrete Mathematics, 19 (1) (2013), 73-83.

[34] Z. J. Sun, L. ZHu, On New Wilker-Type Inequalities, ISRN Math. Anal., 2011, 7 pages, Article ID 681702.

[35] Z. J. Sun, L. Zhu, Some Refinements of Inequalities for Circular Functions, J. Appl. Math., 2011, 9 pages, Article ID 869261.

[36] Z. J. Sun, L. ZHu, Simple proofs of the Cusa-Huygens-type and Becker-Stark-type inequalities, J. Math. Inequal., 7 (4) (2013), 563-567.

[37] S. Wu, On extension and refinement of Wilker's inequality, Rocky Mountain J. Math., 39 (2) (2009), 683-687.

[38] Z. H. YANG, Refinements of a two-sided inequality for trigonometric functions, J. Math. Inequal., 7 (4) (2013), 601-615.

[39] Z. H. YANG, New sharp Jordan type inequalities and their applications, Gulf J. Math., 2 Issue 1 (2014), 1-10.

[40] Z. H. YANG, The sharp inequalities related to Wilker type, Math. Inequal. Appl., 17 (3) (2014), 10151026.

[41] Z. H. Yang, Y. M. ChU, A Note on Jordan, Adamović-Mitrinović, and Cusa Inequalities, Abstr. Appl. Anal., 2014, 12 pages, Article ID 364076.

[42] L. ZhANG, L. ZHU, A new elementary proof of Wilker's inequalities, Math. Inequal. Appl., 11 (1) (2007), 149-151.

[43] L. ZHU, A New Simple Proof of Wilker's Inequality, Math. Inequal. Appl., 8 (4) (2005), 749-750.

[44] L. ZHU, Sharpening Jordan's inequality and the Yang Le inequality I, Appl. Math. Lett., 19 (2006), 240-243. 
[45] L. ZHU, Sharpening Jordan's inequality and the Yang Le inequality II, Appl. Math. Lett., 19 (2006) 990-994. 